
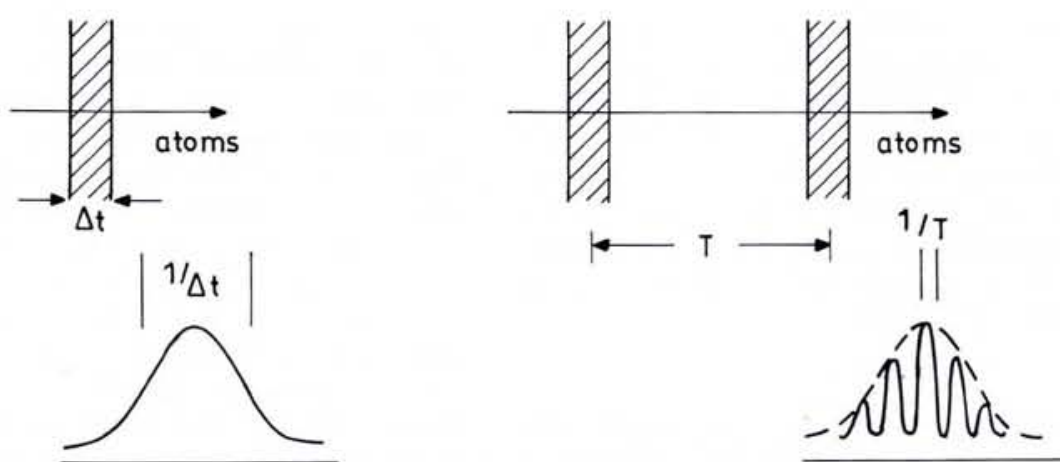

Fig. 3 - The Ramsey technique for two probing fields (right) as compared with the conventional one-field method (left). The left-hand hatched area symbolizes an atom-field interaction region with an interaction time $\Delta t$ while $T$ is the time-of-flight between two regions for the two-field arrangement. The two-field frequency spectrum is analogous to a two-slit interference pattern. Its envelope (dashed line) is equivalent to the one-field spectrum.

In Ramsey's two-field method, the atoms under investigation interact with two fields which are phase coupled (see Fig. 3). Owing to the coherent action of the two fields, the resonance curve is changed and shows an additional "interference" structure. The width of the central narrow peak is determined by the atom's time of flight between the two interaction regions.

The cesium clock, which has been used as a time standard since 1967, is based on this principle. Cesium-133 atoms in a beam are state selected according to their hyperfine states (as in the hydrogen maser). Transitions between the hyperfine levels are induced in the two-field interaction region and detected by means of a second hexapole magnet and a detector. According to the adopted definition of the time standard, the peak of the resonance curve (i.e. the hyperfine splitting), corresponds to exactly $9192631770 \mathrm{~Hz}$.

The two-field method is the basis of experiments aiming to determine the electric dipole moment of the neutron that are currently being undertaken by Norman Ramsey and collaborators at the ILL, Grenoble. The accuracy of the

\section{The 1989 Nobel Laureates}
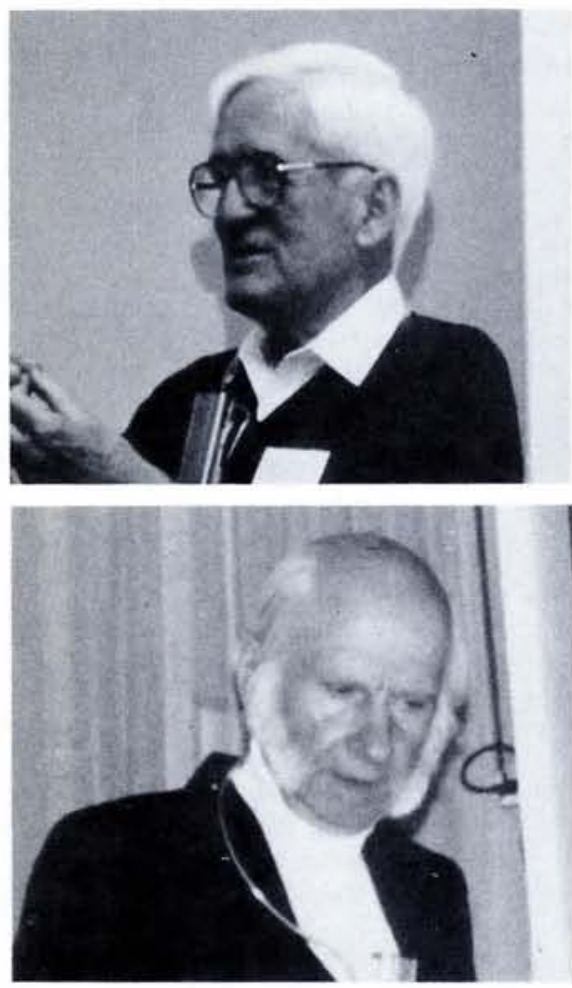

The 1989 Nobel laureates:Norman Ramsey (top), Hans Dehmelt (bottom) and Wolfgang Paul (top right).

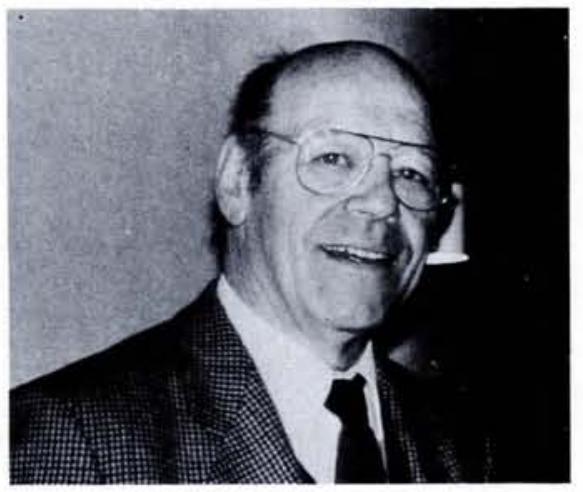

Norman Ramsey was appointed to the faculty of Harvard University in 1947 and retired recently as the Higgins Professor of Physics. He remains very active in lecturing and research, commuting regularly to the ILL, Grenoble where he continues his collaboration using the Institute's cold neutron facility. A graduate of Columbia University, he received his Ph.D. in 1940. After working at the MIT Radiation Laboratory and on the Manhattan Project, he returned to Columbia as an associate professor. He helped found Associate Universities Inc., the group that created the experiment at the present time gives an upper limit of $5 \times 10^{-25} \mathrm{e.cm}$ for the electric dipole moment.

The Nobel laureates of 1989 have clearly set the stage for a series of precision experiments in atomic spectroscopy. The field is still undergoing rapid development so further interesting results and applications relating to precision measurements must be expected in the near future.

\section{FURTHER READING}

[1] For a review of the history of the $g-2$ experiments, see: Dehmelt H.G. in: Advances in Laser Spectroscopy, Eds. F.T. Arecchi, F. Strumia and $\mathrm{H}$. Walther (Plenum Press, New York) 1983; Ekstrom P. and Wineland D., Scientific American 243 (1980) 104.

[2] For the original description of the Paul trap: Paul W., Osberghaus $\mathrm{O}$. and Fischer E., Ein lonenkäfig (Forschungsberichte des Wirtschafts- und Verkehrsministeriums, Nordrhein-Westfalen) 1958.

[3] On ion traps, laser cooling, quantum jumps, etc.: Itano W.M., Bergquist J.C. and Wineland D.J., Science 237 (1987) 612.

[4] On phase transitions and chaos: Quint W., Schleich W. and Walther H., Physics World 2 (1989) 30 and La Recherche 20 (1989) 1194.

[5] On Ramsey's method: Ramsey N.F., Physics Today (July 1980) 25.

[6] On atomic clocks: Hellwig H., Evenson K.M. and Wineland D.J., Physics Today (December 1978) 23.

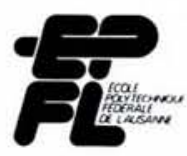

The group of electronic ceramics at the Swiss Federal Institute of Technology in Lausanne has the following openings:

Research associates (post-doctoral fellows):

1. Electrical properties of ferroelectrics and high- $K$ dielectrics

2. Processing of ferroelectric ceramics

3. Crystallographic study of electronic materials

Doctorate students:

1. Ferroelectric materials

2. Microwave ceramics

Submit applications to:

Prof. N. Setter

Département des matériaux EPFL

34, chemin de Bellerive

CH - 1007 Lausanne

Switzerland 
Brookhaven National Laboratory, becoming its Executive Secretary, and from 1946 to 1947 the first Chairman of its Physics Department.

Norman Ramsey has contributed much to the physics community. In 1962, he chaired the committee which assessed the future US needs for high energy physics. This interest matured by his becoming, from 1966 to 1981 , the first President of the Universities Research Association, the consortium set up to operate what eventually became Fermilab. Professor Ramsey has served as the President of the American Physical Society and as the chairman of its governing board.

Hans Dehmelt, born in Görlitz, Germany, has been a professor at the Physics Department, University of Washington, Seattle since 1955 . He remains an active researcher, leading a group that continues to develop ion traps. Together with his thesis advisor Hubert Krueger in Hans Kopfermann's Institute at the Georg August Uni- versity in Göttingen, he developed the nuclear electric quadrupole resonance technique for which he received his Ph.D. in physics in 1950. He remained at the institute as a Research Fellow until 1952 before taking up a research post at Duke University. He was awarded the DavissonGerme Prize of the American Physical Society in 1970.

Wolfgang Paul, a member of the EPS from the very beginning, was born in Lorenzkirch, Germany. He retired in 1989 as Professor of Experimental Physics and Director of the Physikalisches Institut of the University of Bonn to which he was appointed in 1952. Professor Paul studied at the Technical Universities of Munich and Berlin, receiving his doctorate in 1939 for work carried out with Hans Kopfermann. He moved with his thesis advisor to the University of Kiel, and to the University of Göttingen where he was appointed assistant professor. He has persued re- search interests in several fields, ranging from high resolution spectroscopy to radiobiology.

Wolfgang Paul initiated high energy physics in the FRG by launching the construction of a $500 \mathrm{MeV}$ electron synchrotron in Bonn, the first in Europe to use the strong focussing technique. This was followed nearly ten years later by a $2.5 \mathrm{Gev}$ accelerator. He has been a Director at both DESY, Hamburg and KFA, Jülich and from 1964 to 1967 became the first joint Head of Nuclear Physics Division and later the Director of Physics I Department at CERN. He served on the science policy committees of DESY and of CERN in its formative years from 1975 to 1977 , when the 400 Gev SPS proton synchrotron was commissioned. He has also collaborated with the ILL, Grenoble since the late 1970's where his most recent research involving bottled neutrons was only completed last year. He continues to serve German science as President of the Alexander von Humboldt Foundation.

\section{New Members of the European Physical Society}

\section{CATEGORY 4a)}

P.G. Boswell, Geneva, $\mathrm{CH}$ G.F. Chouteau, Grenoble, F P.W. Lucas, Batavia, IL, USA S.C. Schaller, Los Alamos, NM, USA

M. Thuot, Los Alamos, NM, USA

\section{CATEGORY 4c)}

\section{Austrian Physical Society}

T. Laloyaux, Thuin

\section{French Physical Society}

P. Aimedieu, Verrières-le-Buisson

Y. Berthier, St. Martin d'Hères

J.M. Besson, Marseille

P. Bonnet, Paris

J. Cadot, Dijon

B. Cagnac, Paris

J.-L. Chotin, Le Vésinet

D. Chochet Munchy, Grenoble

D. Escande, Marseille

H. Flocard, Orsay

L. Laurent, Aix-en-Provence

A. Leger, Paris

S. Lequiem, Marcoussis

$X$. Litaudon, St. Paul-lez-Durance

Y. Maréchal, St. Ismier

L. Marquez, Gradignan

P. Marin, Orsay

C. Marty, Antony

N. Marty, Antony

O. Peyrusse, Paris

P. Pignet, Villeneuve d'Ascq

D. Puy, Meudon

J.-M. Rax, St. Paul-lez-Durance

S. Reynaud, Cachan

Z.H. Sirousse, Paris

A. Viallat, St. Martin d'Hères

Polish Physical Society

T. Dohnalik, Krakow

M. Kaczmarek, Oxford, GB
German Physical Society

R. Becker, Heidelberg

U.C. Bertram, Cambridge, GB

G. Dodis, Patras, GR

J. Freund, Seattle, WA, USA

M. Graf, St. Ouen, F

R.M. Kenn, Wöllstein

H. Müllejans, Cambridge, GB

E. Neugebauer, Siegen

H. Ostermeier, Oberhinkofen

J.-H. Rechtien, Osnabrück

H. Riecke, Evanston, IL, USA

S. Sack, Hamburg

J. Stein, Goldbach

J. Steinkamp, Hamburg

H.-G. Vossenberg, Braunschweig

M.H. Wappelhorst, London, GB

Hellenic Physical Society

T. Karakasidis, Thessaloniki

Italian Physical Society

F. Bevilacqua, Pavia

S.S. D'Agostino, Rome

L. Lo Monaco, Catania

G. Majni, Ancona

\section{The Netherlands' Physical} Society

W.P.J. Heubers, Amsterdam

J.G. van der Laan, Petten

J. van Turnhout, Delft

Norwegian Physical Society

S. Raaen, Trondheim

Physical Section, Union of Yugoslav Societies of Mathematicians, Physicists and Astronomers

D. Jovanovic, Belgrade

V. Miljevic, Belgrade
Physical Society of the German

Democratic Republic

J. Schneider, Dresden

Physical Section, Union of Czechoslovak Mathematicians and Physicists

J. Cermak, Revnice

Spanish Royal Society of Physics J.E. Alvarellos, Madrid

J. Bernabeu, Burjasot

A. Calvo-Hernandez, Salamanca

Swedish Physical Society

M. Salehpour, Uppsala

The Institute of Physics

R.W. Adama-Acquah, Leicester

M.G. Albow, Enskede, S

A.M. Al-Saie, State of Bahrain

R. Barrett, London

J.R. Best, Fleet

V. Casey, Limerick, IRL

C.W. Chan, Treharris

J. Cole, Exmouth

J.L.N. Conway, Harrow

G.R.J. Cooper, Jo-burg, RSA

G. Danby, Norman, OK, USA

T.C. Davies, Munich, D

A.J.Denyer, Bridgend

S. Dillon, Goole

W.H. Drake, Zomba, Malawi

D.A. Dunmur, Sheffield

M. Ebrahimzadeh, North Haugh

A.M. Eiro, Lisbon, P

I.M. Every, Milton Keynes

M.R. Gadsdon, Maidenhead

V.S. Garg, Samchi, Bhutan

S. Hag, Cambridge

L.O. Heeney, Balbriggan, IRL

R.T. Herrod, East Molesey

M.C. Holland, Glasgow

S. ljaha, London
C. Jeynes, Guildford

M.K. Khan, Manchester

S. Kuldip, Ludhiana, Punjab, India

N.J. Leaman, Glasgow

A.E. Lees, Rugby

D. Leong, Kingston-upon-Thames

J. Mahanty, Canberra, Australia

M. Martinis, Zagreb, YU

G.R. Moridi, Suva, Fiji

K.S.P. Mylvaganam, Fantoft, N

S.B. Palmer, Coventry

C. Patel, North Harrow

T.E. Peacock, St. Lucia, Australia

G.A. Phillips, Cardiff

S.N. Rai, Shillong, Meghaliaya, India

J.C. Read, Solihull

A.J. Sandbach, Sandbach

K. Savvidou, Evrykhou Solea, Cyprus

L.M. Shoobridge, Gaborone, Botswana

G.W.D. Spratt, Tokyo, Japan

M.J. Stokes, Kowloon, Hong Kong

S. Swain, Belfast

K.S. Tan, Bandar Seri Begawan, Brunei

M.T. Tavassoli, Tehran, Iran

T. El-Dessouki, Cairo, Egypt

J.O. Uhomoibhi, Belfast

E. Whelan, Altrincham

A. Wood, Hythe

S. Zindi, Harare, Zimbabwe

\section{CATEGORY 4d)}

American Physical Society

P. Huerre, Palaiseau, F

Y.J. Nikas, Leuven, B

J.A. Sauls, Evanston, IL

Canadian Association of Physics D.A. Dohan, Vancouver

French Optical Society

J.-P. Meunier, Saint Etienne 